\title{
Retrospective study of prognosis of patients with multiple colorectal carcinomas: synchronous versus metachronous makes the difference
}

\author{
Christoph Barz $^{1} \cdot$ Christian Stöss $^{1}$ • Philipp-Alexander Neumann ${ }^{1} \cdot$ Dirk Wilhelm $^{1} \cdot$ Klaus-Peter Janssen ${ }^{1}$. \\ Helmut Friess ${ }^{1} \cdot$ Ulrich Nitsche $^{1}$ (10)
}

Accepted: 6 April 2021 / Published online: 14 April 2021

(C) The Author(s) 2021

\begin{abstract}
Purpose Little is known about difference between synchronous colorectal cancer (SCRC) and metachronous colorectal cancer (MCRC) despite the relevance for this selected patient group. The aim of this retrospective review was to analyze patients with SCRC and MCRC.

Methods All patients who underwent surgery for SCRC and MCRC between 1982 and 2019 were included in this retrospective analysis of our tertiary referral center. Clinical, histological, and molecular genetic characteristics were analyzed. The primary endpoint was cause-specific survival, evaluated by the Kaplan-Meier method. Secondary endpoints were recurrence-free survival and the identification of prognostic factors.

Results Overall, 3714 patients were included in this analysis. Of those, $3506(94.4 \%)$ had a primary unifocal colorectal cancer (PCRC), 103 (2.7\%) had SCRC, and 105 (2.8\%) had MCRC. SCRC occurred more frequently in elderly $(p=0.009)$ and in male patients $(p=0.027)$. There were no differences concerning tumor stages or grading. Patients with SCRC did not show altered recurrence or survival rates, as compared to unifocal tumors. However, MCRC had a lower rate of recurrence, compared to PCRC ( $24 \%$ vs. $41 \%, p=0.002)$ and a lower rate of cause-specific death $(13 \%$ vs. $37 \%, p<0.001)$. Five-year cause-specific survival rates were $63 \pm 1 \%$ for PCRC, $62 \pm 6 \%$ for SCRC $(p=0.588)$, and $88 \pm 4 \%$ for MCRC $(p<0.001)$. Multivariable analysis revealed that $\mathrm{MCRC}$ were an independent favorable prognostic parameter regarding case-specific survival.

Conclusion Patients with SCRC seem to not have a worse prognosis compared to patients with PCRC. Noteworthy, patients with MCRC showed better survival rates in this retrospective analysis.
\end{abstract}

Keywords Colorectal cancer $\cdot$ Multiple cancers $\cdot$ Synchronous cancers $\cdot$ Prognosis

\section{Introduction}

Colorectal cancer $(\mathrm{CRC})$ is the third most common cancer in the western world [1]. By far most of these patients present with a primary unifocal adenocarcinoma of the colorectum (PCRC), which enables treatment according to established and validated guidelines [2]. However, in about $2-8 \%$ of all patients, synchronous multiple CRC (SCRC) are diagnosed at the time of diagnosis or during postoperative pathologic

Christoph Barz and Christian Stöss contributed equally to this work.

Ulrich Nitsche

ulrich.nitsche@tum.de

1 Klinikum rechts der Isar, Department of Surgery, School of Medicine, Technical University of Munich, Ismaninger Str. 22, 81675 Munich, Germany examination [3-5]. Further, albeit it may be sometimes difficult to discriminate from a recurrence of the initial tumor, about $1.6-2.4 \%$ of patients who undergo a complete resection (R0) of their primary colorectal cancer will develop a second, metachronous colorectal cancer (MCRC) during follow-up. MCRC was described to have a higher age-corrected incidence than compared to healthy controls who did not have colorectal cancer before [6-9]. Due to their relative rare occurrence, available clinical data on SCRC and MCRC is limited. Some authors postulated that sporadic (non-HNPCC and non-APC) SCRCs have a high molecular inter-tumoral homogeneity and may be associated with the MSI-/BRAF-pathway, leading to reduced overall survival $[3,10]$. Others describe SCRC to have essentially different driver mutations in the tumor-associated genes KRAS, BRAF, and p53 - and a comparable or even slightly better prognosis than classical unifocal tumors [5, 11]. For MCRC, in the limited literature 
available, the mean time to occurrence is estimated approximately 4 years after the initial colorectal cancer [2]. This is considerably later compared to the "classical" local/regional tumor recurrence, of which $80 \%$ of all cases occur within the first 2 years after initial treatment [2]. Finally, patients with SCRC seem to have a 3- to 6-fold higher chance for developing MCRC $[6,7,12]$.

Still many uncertainties exist for SCRC or MCRC. It is not clear whether these patients bear specific histological characteristics, accompanied by a distinct recurrence and survival profile. Here, we sought to analyze the impact on multiple cancers within identical patients on oncological outcomes and disease progression.

\section{Materials and methods}

\section{Study population}

Since 1982, all patients undergoing surgery for colorectal cancer at the Department of Surgery, Klinikum rechts der Isar, Technische Universität München, Munich, Germany, are scheduled for periodic follow-up either at our interdisciplinary outpatient tumor center or outside of the hospital and according to the recommendations of the German Cancer Society. All patient data are prospectively entered to a data base. The ethics committee of the Klinikum rechts der Isar approved the study (no. 1926/7). Informed written consent was obtained from all patients prior to the collection of data. This observational cohort study was drafted in accordance with the STROBE statement (http://www.strobe-statement.org).

For the present analysis, consecutive complete datasets of patients with surgery for PCRC, SCRC, or MCRC were extracted. In order to report on consecutive data sets and to avoid selection bias, patients with missing follow-up data (Table 1) were not excluded. Patients with proven or suspected familial adenomatous polyposis (FAP) or hereditary nonpolyposis colorectal cancer (HNPCC), patients with proven or suspected tumor recurrence (see definitions below), and patients with an uncertain past medical history regarding prior malignancies were not included. The latest date of inclusion and follow-up was July 2019. Clinical histopathological, molecular genetic, and follow-up data (recurrence/survival) of patients with PCRC were compared to those of patients with SCRC and MCRC.

\section{Definitions of synchronous and metachronous cancer}

In the absence of generally accepted definitions, we considered patients to have SCRC if more than one histologically proven malignant lesion was present within the colon and/or rectum at the index assessment, clearly separated by healthy mucosa $[4,5]$. The exact time point of diagnosis might vary between the preoperative (colonoscopy), intraoperative, or postoperative (histological workup of the resected specimen) time point. A complete colonoscopy was sought for all patients, which may have included a postoperative investigation of the remaining colon after resection of an obstructing tumor of the rectum or left colon. We considered patients to have MCRC, if they were diagnosed free of tumor for at least 12 months after initial treatment for colorectal cancer, and then during follow-up had a new, histological proven malignant lesion within the colon and/or rectum. The new lesion had to be divided from any anastomotic region of prior treatments by healthy mucosa and had to be unambiguously an exulcerating epithelial carcinoma. By this, the risk of overestimating the MCRC rate due to local or regional (nodal, etc.) tumor recurrences of prior occurrences was reduced to the minimum.

\section{Statistical analysis}

Statistical evaluation was performed using IBM $®$ SPSS $®$ statistics Version 24 (SPSS Inc., IBM Corporation Software Group, Somers, NY, USA). The distribution of nominal or ordinal scaled variables was compared using Pearson's chisquare test. Cardinal variables were tested for normal distribution by the Kolmogorov-Smirnov test. Explorative comparison of independent groups was performed by the $t$ test for normal distribution and the Mann-Whitney $U$ test (two groups) or the Kruskal-Wallis test (more than two groups) for non-normal distribution. All statistical tests were performed two-sided, and $p$-values less than 0.05 were considered statistically significant. No correction of $p$-values was applied to adjust for multiple testing. However, results of all statistical tests being conducted were thoroughly reported, so that an informal adjustment of $p$ values can be performed while reviewing the data [13]. Multivariable analysis of binary outcome data was assessed by logistic regression. Time-dependent survival probabilities were estimated with the Kaplan-Meier method, and the log rank (Mantel-Cox) test was used to compare independent subgroups. Cause-specific survival was used as the primary outcome parameter. Cause-specific survival is equivalent to disease-specific survival in relation to the initial malignant disease and considers only tumor-related deaths of the reported malignancy as events. It reflects the intrinsic biology of the colorectal cancer under investigation more precisely than, e.g., cancerspecific survival, which includes deaths due to any kind of cancer [14]. To investigate the effect on survival of multivariable relationships among covariates, Cox proportional hazard models were applied. Cause-specific survival times as well as estimated hazard ratios (HRs) were calculated and reported as $95 \%$ confidence intervals (95\% CIs) [15]. 
Table 1 Characteristics of the complete patient cohort

$n=3714$

3506

Tumor type

Primary unifocal CRC (PCRC)

Synchronous multiple CRCs (SCRC)

Metachronous CRC (MCRC)

103

105

65

Years (median)

2135

Men

Women

Colon versus Rectum (main tumor)

\section{Colon}

Rectum

2203

1511

Localization (all tumors)

Multiple Segments

Right hemicolon

30

1134

Left hemicolon

Rectum

Missing

Preoperative ileus

No ileus

Subileus

Manifest ileus

Missing

Concomitant diseases

No

Yes

Missing

Tumor size

Centimeter (median)

Missing

Multivisceral surgery

No

Yes

Missing

Tumor status

T0

Tis

$\mathrm{T} 1$

$\mathrm{T} 2$

$\mathrm{T} 3$

T4

Missing

Nodal status

N0

N1

$\mathrm{N} 2$

Missing

Metastasis status

M0

46

161

1547

1891

286

2814

691

209

65

23

349

623

1849

616

189

1943

786

763

222

2605
Effect on cause-specific survival

HR 1

$p=0.057$ (HR 1.38; 95\% CI 0.99-1.91)

$p<0.001$ (HR $0.27 ; 95 \%$ CI $0.14-0.52$ )

$p=0.663($ HR $1.00 ; 95 \%$ CI 0.99-1.00)

HR 1

$p=0.088$ (HR 1.11; 95\% CI 0.99-1.25)

HR 1

$p=0.320($ HR $1.06 ; 95 \%$ CI $0.94-1.20)$

HR 1

$p=0.081$ (HR 0,59; 95\% CI 0.32-1.07) $p=0.049$ (HR $0.55 ; 95 \%$ CI $0.30-0.99$ ) $p=0.101$ (HR $0.61 ; 95 \%$ CI $0.33-1.10)$

1491

HR 1

$p<0.001$ (HR 2.16; 95\% CI 1.72-2.70)

80

20 $p<0.001$ (HR 2.40; 95\% CI 1.91-3.03)

$p<0.001$ (HR 1.14; 95\% CI 1.11-1.16)

HR 1

$p<0.001$ (HR $1.65 ; 95 \%$ CI 1.44-1.90)

HR 1

$p<0.001$ (HR 0.89; 95\% CI 0.04-0.20) $p=0.003$ (HR 0.05 ; 95\% CI 0.01-0.45) $p<0.001$ (HR $0.05 ; 95 \%$ CI $0.03-0.08$ ) $p<0.001$ (HR $0.12 ; 95 \%$ CI $0.10-0.16$ ) $p<0.001$ (HR 0.43 ; $95 \%$ CI $0.38-0.49$ )

HR 1 $p<0.001$ (HR 3.26; 95\% CI 2.77-3.85) $p<0.001$ (HR 9.15; 95\% CI 7.88-10.64)

HR 1 
Table 1 (continued)

\begin{tabular}{|c|c|c|c|}
\hline & $n=3714$ & $\%$ & Effect on cause-specific survival \\
\hline M1 & 834 & 24 & $p<0.001$ (HR 10.7; 95\% CI 9.47-12.16) \\
\hline Missing & 275 & & \\
\hline \multicolumn{4}{|l|}{ Stage } \\
\hline $0 /$ Tis & 71 & 2 & HR 1 \\
\hline I & 753 & 22 & $p=0.596$ (HR 0.78; 95\% CI 0.31-1.96) \\
\hline II & 900 & 26 & $p=0.066(\mathrm{HR} 2.31 ; 95 \%$ CI $0.95-5.63)$ \\
\hline III & 860 & 25 & $p<0.001$ (HR 5.99; 95\% CI 2.48-14.50) \\
\hline IV & 834 & 25 & $p<0.001($ HR $31.09 ; 95 \%$ CI 12.88-75.06) \\
\hline Missing & 296 & & \\
\hline \multicolumn{4}{|l|}{ Grading } \\
\hline $\mathrm{G} 1 / 2$ & 2381 & 69 & HR 1 \\
\hline $\mathrm{G} 3 / 4$ & 1064 & 31 & $p<0.001$ (HR 2.20; 95\% CI 1.95-2.48) \\
\hline Missing & 269 & & \\
\hline \multicolumn{4}{|l|}{ Lymphatic invasion } \\
\hline L0 & 2599 & 74 & HR 1 \\
\hline $\mathrm{L} 1$ & 896 & 26 & $p<0.001$ (HR 3.28; 95\% CI 2.90-3.70) \\
\hline Missing & 219 & & \\
\hline \multicolumn{4}{|l|}{ Vascular invasion } \\
\hline V0 & 3187 & 91 & HR 1 \\
\hline V1 & 304 & 9 & $p<0.001$ (HR 3.96; 95\% CI 3.36-4.67) \\
\hline Missing & 223 & & \\
\hline \multicolumn{4}{|l|}{$\mathrm{R}$ status } \\
\hline $\mathrm{R} 0$ & 2781 & 79 & HR 1 \\
\hline $\mathrm{R} 1$ & 107 & 3 & $p<0.001$ (HR 5.94; 95\% CI 4.53-7.79) \\
\hline $\mathrm{R} 2$ & 627 & 18 & $p<0.001(\mathrm{HR} 15.27 ; 95 \%$ CI $13.33-17.50)$ \\
\hline Missing/Rx & 199 & & \\
\hline \multicolumn{4}{|l|}{ Microsatellite status } \\
\hline MSS & 270 & 75 & HR 1 \\
\hline MSI-H & 91 & 25 & $p=0.011(\mathrm{HR} 0.34 ; 95 \%$ CI $0.15-0.78)$ \\
\hline Not performed & 3353 & & \\
\hline \multicolumn{4}{|l|}{ KRAS status } \\
\hline Wildtype & 206 & 65 & HR 1 \\
\hline Mutated & 111 & 35 & $p=0.011($ HR $1.93 ; 95 \%$ CI 1.17-3.19) \\
\hline Not performed & 3397 & & \\
\hline \multicolumn{4}{|l|}{ BRAF status } \\
\hline Wild type & 243 & 86 & HR 1 \\
\hline Mutated & 41 & 14 & $p=0.110($ HR $0.44 ; 95 \%$ CI $0.16-1.21)$ \\
\hline Not performed & 3430 & & \\
\hline \multicolumn{4}{|l|}{ Tumor perforation } \\
\hline No & 2544 & 94 & HR 1 \\
\hline Yes & 171 & 6 & $p<0.001(\mathrm{HR} 2.61 ; 95 \%$ CI 2.02-3.38) \\
\hline Missing & 999 & & \\
\hline \multicolumn{4}{|l|}{ Tumor histology } \\
\hline Classical adenocarcinoma & 3079 & 86 & HR 1 \\
\hline Mucinous adenocarcinoma & 382 & 11 & $p=0.011(\mathrm{HR} 1.27 ; 95 \%$ CI $1.06-1.53)$ \\
\hline Signet-ring cell carcinoma & 32 & 1 & $p<0.001($ HR 3.23; 95\% CI 2.07-5.03) \\
\hline Other types & 65 & 2 & $p<0.001$ (HR 2.34; 95\% CI 1.62-3.39) \\
\hline Missing & 156 & & \\
\hline
\end{tabular}

CEA (ng/ml, median) 
Table 1 (continued)

\begin{tabular}{llll}
\hline & $n=3714$ & $\%$ & Effect on cause-specific survival \\
\hline ng/ml (Median) & 4.0 & 100 & $p<0.001$ (HR 1.00; 95\% CI 1.00->1.00) \\
Not performed & 2491 & & \\
Tumor recurrence & 1874 & 59 & HR 1 \\
No & 1304 & 41 & $p<0.001$ (HR 299.67; 95\% CI 169.42-530.03) \\
Yes & 536 & & \\
Lost of follow-up & & & \\
Survival status & 1457 & 47 & n.a. \\
Alive & 1137 & 37 & n.a. \\
Death cancer-related & 112 & 3 & n.a. \\
Death postoperative & 397 & 13 & n.a. \\
Death other causes & 611 & & \\
Lost of follow-up & & & \\
\hline
\end{tabular}

Absolute numbers of patients together with percentages are displayed, if not indicated otherwise. The right column shows the prognostic relevance for each parameter, regarding case-specific survival upon univariable analysis. Concomitant diseases included any kind of cardiovascular, renal, pulmonary, or other relevant underlying medical conditions. $H R$ hazard ratio, $95 \% C I 95 \%$ confidence interval

\section{Results}

\section{Study population}

Between January 1982 and July 2019, 4367 consecutive patients underwent oncological resection of their histologically proven colorectal cancer(s). Of those, 619 patients had to be excluded because of another, non-colorectal carcinoma before the index operation or during follow-up, in order to minimize bias. Another 32 patients with histologically not further specified colorectal cancer were excluded. Finally, two patients who each had both, SCRC and MCRC, were omitted from the overall analysis, but are described in more detail in the results section. Thus, 3714 resected patients were finally analyzed. Of those 3714 patients, 3506 patients had PCRC (94.4\%), 103 had SCRC (2.8\%), and 105 had MCRC $(2.8 \%)$. The median age of all patients was 65 years (range: 15 to 97 years). There were more men $(n=2135)$ than women $(n=1579)$ in the cohort. The tumors were located within the right hemicolon between cecum and transverse colon in 1134 patients (31\%), within the left hemicolon between descending colon and sigmoid in 1013 patients $(27 \%)$, within the rectum in 1491 patients $(41 \%)$, and in more than one of the above mentioned colorectal segments in 30 patients (in the case of SCRC; $1 \%$ of all patients). For 46 patients, the exact allocation of the tumors to an anatomical segment was not possible. All patients underwent resection of their colorectal tumors. For all 2584 patients without metastasis (stage 0/Tis to III), R0 resection was achieved in $96 \%(n=2481)$. For the 834 patients who presented with distant organ metastasis or peritoneal carcinomatosis (stage IV), an R0 resection was achieved in 19\% $(n=160)$. The median follow-up was 97 months, with no differences for PCRC, SCRC, and MCRC. See Table 1 for further characteristics of the patient cohort.

\section{Comparison of SCRC and MCRC to PCRC}

Age did not differ significantly between patients with PCRC, SCRC, and MCRC. There was a higher proportion of men in the SCRC group (68\% vs. $57 \%$ for PCRC; $p=0.027$ ). In addition, complete tumor obstruction (manifest ileus) was found to be more frequent in patients with SCRC (9\% vs. 5\% in PCRC; $p=0.017$ ). Rectal cancer was present in $41 \%$ of the patients with PCRC, compared to only $28 \%(p<0.001)$ for SCRC and $33 \%$ for MCRC $(p<0.001)$. In $29 \%$ of the patients with SCRC, the synchronous multiple tumors were not in the same segment, while in $71 \%$ of patients with SCRC, all tumors were located within the same segment (proximal colon/distal colon/ rectum). The maximum tumor size of MCRC was significantly smaller $(3.6 \mathrm{~cm}$ vs. $4.0 \mathrm{~cm}$ for PCRC; $p<0.001)$. Patients with MCRC more frequently underwent multivisceral resection of the omentum, small bowel, abdominal wall, bladder, ureter, ovar/adnexes, prostate, pancreas, and others (31\% vs. $19 \%$ for PCRC; $p=0.002$ ). Regarding histopathology, the R0 rate was significantly higher in MCRC patients $(86 \%$ vs. $79 \%$ in PCRC; $p=0.030$ ). High-grade tumors (G3 or G4) occurred more frequently in SCRC ( $43 \%$ vs. $31 \%$ for PCRC; $p=0.008$ ). Although only available in a very limited number of patients, no significant differences occurred in microsatellite instability, KRAS mutations, or BRAF mutations. Of the patients with MCRC, most initial resections were performed at another institution. Thus, only limited information was available regarding the time period between both tumor occurrences, staging, and treatment of the initial tumor. There was no evidence for 
Table 2 Characteristics of singular primary colorectal cancers (PCRC), multiple synchronous colorectal cancers (SCRC), and multiple metachronous colorectal cancers (MCRC)

\begin{tabular}{|c|c|c|c|c|}
\hline $\begin{array}{l}\text { Primary unifocal CRCs } \\
\text { (PCRC) }\end{array}$ & $\begin{array}{l}\text { Multip } \\
\text { (SCRC }\end{array}$ & hr. CRCs & $p(\mathrm{PCRC}$ vs SCRC) & $\begin{array}{l}\text { Metachr. CRC } \\
\text { (MCRC) }\end{array}$ \\
\hline$n=3506$ & $n=103$ & $\%$ & & $n=105$ \\
\hline
\end{tabular}

\section{Patient age}

Years (median)

64

Gender

Men

Women

64

100

68

100

0.009

$p$ (PCRC vs MCRC)

olon versus rectum (main tumor)

\section{Colon \\ Rectum \\ Localization}

1999

1507

$\begin{array}{ll}57 & 70 \\ 43 & 33\end{array}$

68

0.027

32

2060

1446

$59 \quad 70$

41

68

100

0.062

0.061

$\begin{array}{ll}66 & 63 \\ 39 & 37\end{array}$

0.233

73

32

70

0.027

Multiple segments

Right hemicolon

0

Left hemicolon

1069

968

1429

40

Rectum

Preoperative ileus

$\begin{array}{ll}\text { No ileus } & 2995 \\ \text { Subileus } & 192 \\ \text { Manifest ileus } & 164 \\ \text { Missing } & 155 \\ \text { Concomitant diseases } & \end{array}$

No

1497

Yes

0.003

0.017

$$
<0.001
$$

Missing

4.0

273

$$
100
$$

27
68

Centimeter (median)

Missing

Multivisceral surgery

No

Yes

2666

640$$
81
$$

Missing

200

19

62

umor status

T0

Tis

T1

$\mathrm{T} 2$

$\mathrm{T} 3$

T4

Missing

Nodal status

N1

N2

21

334

591

1737

580

181

1832

740

722

212

$\begin{array}{ll}2 & 2 \\ 1 & 0 \\ 10 & 5 \\ 18 & 11 \\ 52 & 62 \\ 17 & 20 \\ & 3\end{array}$

100

0.054

81
19

0.979

Missing

2455

792

$\begin{array}{ll}76 & 73\end{array}$

259

$\begin{array}{ll}56 & 47 \\ 22 & 24 \\ 22 & 29 \\ & 3\end{array}$

47

24

29

0.301

$\begin{array}{ll}64 & 65 \\ 22 & 23 \\ 12 & 12 \\ 7 & \end{array}$

0.670

77

83

0.111

M1

$24 \quad 26$

26

16
12

$<0.001$

37

30

33

6

$\begin{array}{lll}88 & 88 & 0.956 \\ 7 & 7 & \\ 5 & 5 & \\ 5 & & \end{array}$

$\begin{array}{lll}23 & 23 & <0.001 \\ 76 & 77 & \\ 6 & & \end{array}$

$\begin{array}{lll}3.6 & 100<0.001\end{array}$

$\begin{array}{lll}69 & 68 & 0.002 \\ 33 & 32 & \end{array}$

Stage 
Table 2 (continued)

\begin{tabular}{|c|c|c|c|c|c|c|c|c|}
\hline & \multicolumn{2}{|c|}{$\begin{array}{l}\text { Primary unifocal CRCs } \\
\text { (PCRC) }\end{array}$} & \multicolumn{2}{|c|}{$\begin{array}{l}\text { Multiple synchr. CRCs } \\
\text { (SCRC) }\end{array}$} & \multirow[t]{2}{*}{$p(\mathrm{PCRC}$ vs SCRC) } & \multicolumn{2}{|c|}{$\begin{array}{l}\text { Metachr. CRC } \\
\text { (MCRC) }\end{array}$} & \multirow[t]{2}{*}{$p$ (PCRC vs MCRC) } \\
\hline & $n=3506$ & $\%$ & $n=103$ & $\%$ & & $n=105$ & $\%$ & \\
\hline $0 /$ Tis & 68 & 2 & 2 & 2 & \multirow[t]{6}{*}{0.262} & 1 & 1 & \multirow[t]{6}{*}{0.153} \\
\hline I & 716 & 22 & 14 & 14 & & 23 & 25 & \\
\hline II & 843 & 26 & 27 & 27 & & 30 & 33 & \\
\hline III & 809 & 25 & 30 & 31 & & 21 & 23 & \\
\hline IV & 792 & 25 & 26 & 26 & & 16 & 18 & \\
\hline Missing & 278 & & 4 & & & 14 & & \\
\hline \multicolumn{9}{|l|}{ Grading } \\
\hline G1/2 & 2254 & 69 & 57 & 57 & \multirow[t]{3}{*}{0.008} & 70 & 71 & \multirow[t]{3}{*}{0.787} \\
\hline $\mathrm{G} 3 / 4$ & 992 & 31 & 43 & 43 & & 29 & 29 & \\
\hline Missing & 260 & & 3 & & & 6 & & \\
\hline \multicolumn{9}{|l|}{ Lymphatic invasion } \\
\hline L0 & 2451 & 74 & 67 & 68 & \multirow[t]{3}{*}{0.206} & 81 & 79 & \multirow[t]{3}{*}{0.202} \\
\hline L1 & 843 & 26 & 32 & 32 & & 21 & 21 & \\
\hline Missing & 212 & & 4 & & & 3 & & \\
\hline \multicolumn{9}{|l|}{ Vascular invasion } \\
\hline V0 & 3002 & 91 & 91 & 92 & \multirow[t]{3}{*}{0.622} & 94 & 93 & \multirow[t]{3}{*}{0.497} \\
\hline V1 & 289 & 9 & 8 & 8 & & 7 & 7 & \\
\hline Missing & 215 & & 4 & & & 4 & & \\
\hline \multicolumn{9}{|l|}{$\mathrm{R}$ status } \\
\hline $\mathrm{R} 0$ & 2621 & 79 & 75 & 77 & \multirow[t]{4}{*}{0.875} & 85 & 86 & \multirow[t]{4}{*}{0.030} \\
\hline $\mathrm{R} 1$ & 99 & 3 & 2 & 2 & & 6 & 6 & \\
\hline $\mathrm{R} 2$ & 599 & 18 & 20 & 21 & & 8 & 8 & \\
\hline Missing/Rx & 187 & & 6 & & & 6 & & \\
\hline \multicolumn{9}{|l|}{ Microsatellite status } \\
\hline MSS & 257 & 75 & 5 & 62 & 0.617 & 8 & 89 & 0.604 \\
\hline MSI-H & 87 & 25 & 3 & 38 & & 1 & 11 & \\
\hline Not performed & 3162 & & 95 & & & 96 & & \\
\hline KRAS status & & & & & & & & \\
\hline Wildtype & 196 & 66 & 5 & 62 & 0.949 & 5 & 50 & 0.530 \\
\hline Mutated & 103 & 34 & 3 & 38 & & 5 & 50 & \\
\hline Not performed & 3207 & & 95 & & & 95 & & \\
\hline BRAF status & & & & & & & & \\
\hline Wildtype & 228 & 85 & 8 & 100 & 0.485 & 7 & 100 & 0.537 \\
\hline Mutated & 41 & 15 & 0 & 0 & & 0 & 0 & \\
\hline Not performed & 3237 & & 95 & & & 98 & & \\
\hline Tumor perforation & & & & & & & & \\
\hline No & 2381 & 94 & 82 & 98 & 0.037 & 81 & 94 & 0.104 \\
\hline Yes & 164 & 6 & 2 & 2 & & 5 & 6 & \\
\hline Missing & 961 & & 19 & & & 19 & & \\
\hline Tumor histology & & & & & & & & \\
\hline Classical adenocarcinoma & 2899 & 86 & 92 & 91 & 0.414 & 88 & 85 & 0.508 \\
\hline Mucinous adenocarcinoma & 364 & 11 & 6 & 6 & & 12 & 12 & \\
\hline Signet-ring cell carcinoma & 29 & 1 & 1 & 1 & & 2 & 2 & \\
\hline Others & 62 & 2 & 2 & 2 & & 1 & 1 & \\
\hline Missing & 152 & & 2 & & & 2 & & \\
\hline CEA (ng/ml, median) & & & & & & & & \\
\hline ng/ml (Median) & 4.0 & 100 & 5.0 & 100 & 0.319 & 3.0 & 100 & 0.166 \\
\hline Not performed & 2332 & & 77 & & & 82 & & \\
\hline
\end{tabular}

Tumor recurrence 
Table 2 (continued)

\begin{tabular}{|c|c|c|c|c|c|c|c|c|}
\hline & \multicolumn{2}{|c|}{$\begin{array}{l}\text { Primary unifocal CRCs } \\
\text { (PCRC) }\end{array}$} & \multicolumn{2}{|c|}{$\begin{array}{l}\text { Multiple synchr. CRCs } \\
\text { (SCRC) }\end{array}$} & \multirow[t]{2}{*}{$p(\mathrm{PCRC}$ vs SCRC $)$} & \multicolumn{2}{|c|}{$\begin{array}{l}\text { Metachr. CRC } \\
\text { (MCRC) }\end{array}$} & \multirow[t]{2}{*}{$p(\mathrm{PCRC}$ vs MCRC $)$} \\
\hline & $n=3506$ & $\%$ & $n=103$ & $\%$ & & $n=105$ & $\%$ & \\
\hline No & 1772 & 59 & 42 & 49 & \multirow[t]{3}{*}{0.476} & 60 & 76 & \multirow[t]{3}{*}{0.002} \\
\hline Yes & 1241 & 41 & 44 & 51 & & 19 & 24 & \\
\hline Lost of follow-up & 493 & & 17 & & & 26 & & \\
\hline \multicolumn{9}{|l|}{ Alive status } \\
\hline Alive & 1371 & 46 & 31 & 38 & \multirow[t]{5}{*}{0.189} & 55 & 69 & \multirow[t]{5}{*}{$<0.001$} \\
\hline Death cancer-related & 1090 & 37 & 37 & 56 & & 10 & 13 & \\
\hline Death postoperative & 108 & 4 & 1 & 1 & & 3 & 4 & \\
\hline Death other causes & 374 & 13 & 12 & 15 & & 11 & 14 & \\
\hline Lost of follow-up & 563 & & 22 & & & 26 & & \\
\hline
\end{tabular}

The $p$-values refer to the comparison of PCRC to SCRC, respective PCRC to MCRC, as indicated

$p$-values in the heading line of each category indicate, if there is an overall difference between the groups when more than two specifications are possible. $p$-values in the same line with the respective specification compare the latter to the specification above

\section{a) Cause-specific survival}

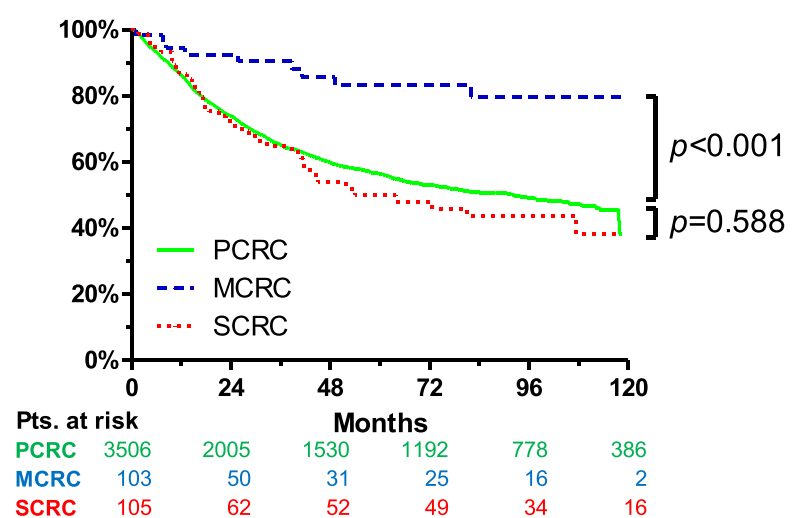

b) Recurrence-free survival

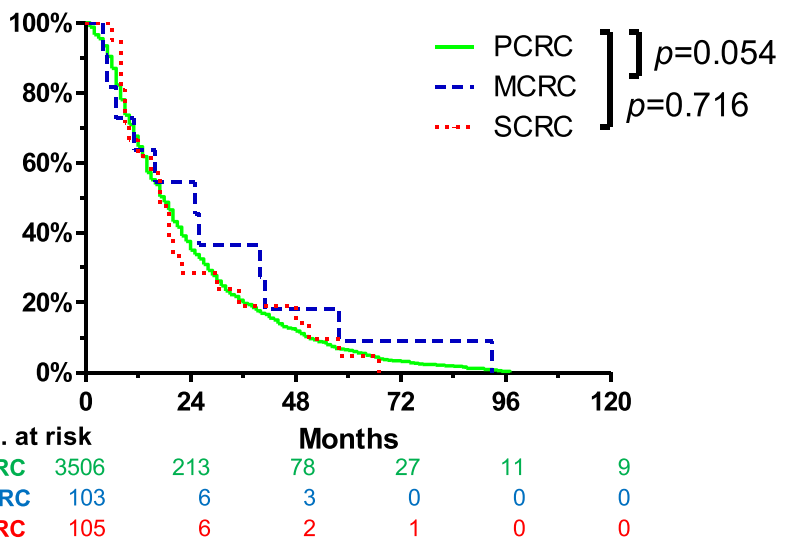

Fig. 1 Cause-specific survival (a) and recurrence-free survival (b) of patients with primary colorectal cancer (PCRC), multiple synchronous colorectal cancer (SCRC), and multiple metachronous colorectal cancer (MCRC). Kaplan-Meier curves showed a clear survival benefit for MCRC, compared to PCRC and SCRC. In contrast to survival data, for recurrence free survival, a considerable reduced number of validated patient data were available for SCRC and MCRC. Thus, the informative value of Kaplan-Meier curve (b) may be limited hereditary forms of SCRC and MCRC in the analyzed cohort, respectively. See Table 2 for characteristics of patients stratified for PCRC, SCRC, and MCRC.

\section{Survival}

While tumor recurrence rates during follow-up was comparable for PCRC (41\%) and SCRC (51\%; $p=0.476)$, MCRC had a significantly lower rate of recurrence $(24 \%, p=0.002)$. These results are in line with the Kaplan-Meier analyses, where MCRC had a significantly better cause-specific survival compared to PCRC and SCRC. Interestingly, no significant differences were observed between the groups for recurrence-free survival (see Fig. 1 for survival rates stratified by PCRC, SCRC, and MCRC). Five-year cause-specific survival rates were $63 \pm 1 \%$ for PCRC, $62 \pm 6 \%$ for SCRC ( $p=0.588)$, and $88 \pm 4 \%$ for MCRC $(p<0.001)$. Median cause-specific survival was not reached for PCRC and MCRC. For SCRC, median cause-specific survival was 63.9 months (95\% CI 10 to 118 ). No significant differences in survival between patients with colon cancer and rectal cancer were observed among the PCRC $(p=0.260)$, SCRC $(p=0.903)$, and MCRC groups $(p=0.130)$. Figure 2 shows the cause-specific survival of patients with PCRC, SCRC, and MCRC, stratified by colon cancer versus rectal cancer.

\section{Prognosis of SCRC and MCRC}

Compared to PCRC, patients with SCRC had a slightly, but not significantly, increased hazard ratio for cause-specific death $(p=0.057$; HR $1.38 ; 95 \%$ CI $0.99-1.91)$. In contrast, patients with MCRC had a significantly better prognosis $(p<0.001$; HR 0.27 ; 95\% CI $0.14-0.52)$. Further, factors 
a) PCRC

Cause-specific survival

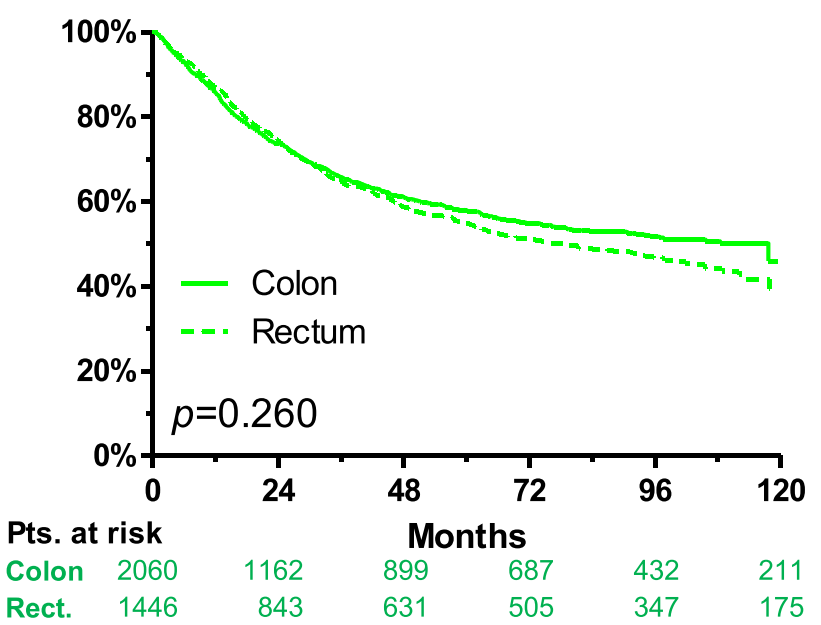

b) SCRC

Cause-specific survival

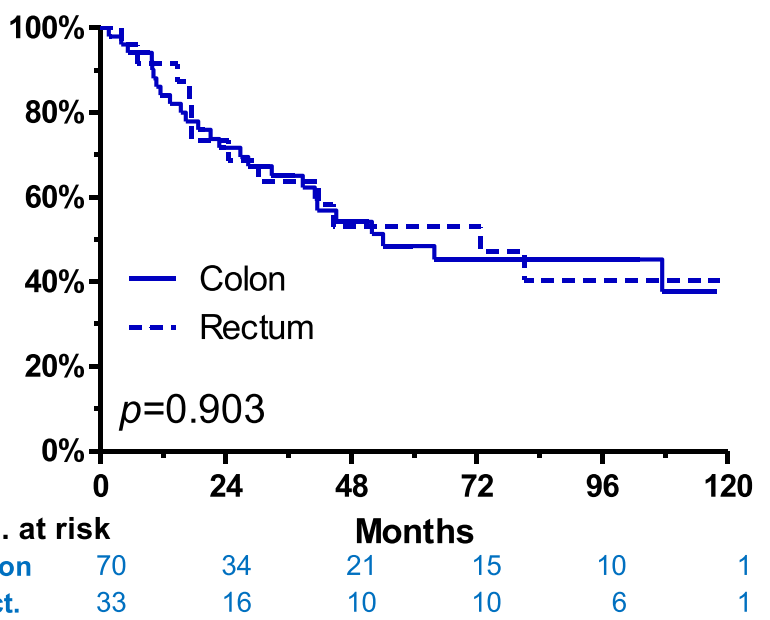

c) MCRC

Cause-specific survival

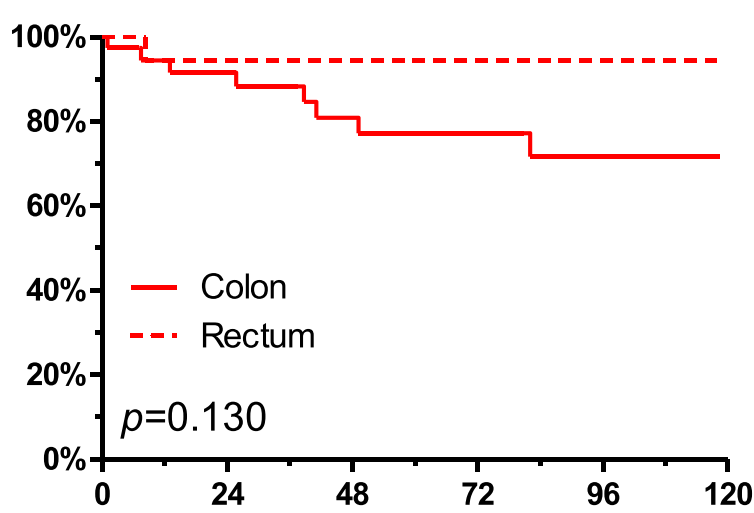

Pts. at risk

Colon 73

Rect. $\quad 32$
Months

\begin{tabular}{rrrrr} 
& \multicolumn{1}{l}{ Months } & & & \\
22 & 33 & 31 & 21 & 11 \\
22 & 19 & 18 & 13 & 5
\end{tabular}

Fig. 2 Cause-specific survival of patients with (a) PCRC, (b) SCRC, and (c) MCRC, stratified by colon cancer versus rectal cancer. No difference was observed between colon and rectal cancer for each spatial tumor manifestation

associated with a reduced prognosis upon univariable analysis are listed below: preoperative manifest ileus $(p<0.001$; HR 2.40 ; $95 \%$ CI 1.91-3.03), extensive tumor size $(p<0.001$; per centimeter: HR 1.14; 95\% CI 1.11-1.16), multivisceral surgery ( $p<0.001$; HR $1.65 ; 95 \%$ CI 1.44-1.90), high T, N, $\mathrm{M}$, and UICC stage ( $p<0.001$ for each), G3/4 vs. G1/2 $(p<0.001$; HR $2.20 ; 95 \%$ CI 1.95-2.48), L1 (lymphatic

Table 3 Multivariable analysis as described in the text

\begin{tabular}{|c|c|c|c|c|}
\hline & \multirow[t]{2}{*}{$p$} & \multirow[t]{2}{*}{$\mathrm{HR}$} & \multicolumn{2}{|c|}{$95 \% \mathrm{CI}$} \\
\hline & & & Lower & Upper \\
\hline \multicolumn{5}{|l|}{ Tumor type } \\
\hline Primary unifocal CRC (PCRC) & 0.010 & 1 & & \\
\hline Multiple synchronous CRC (SCRC) & 0.264 & 1.28 & 0.83 & 1.98 \\
\hline Metachronous CRC (MCRC) & 0.005 & 0.25 & 0.09 & 0.66 \\
\hline \multicolumn{5}{|l|}{ Tumor size } \\
\hline Centimeter (continuously) & 0.016 & 1.05 & 1.01 & 1.09 \\
\hline \multicolumn{5}{|l|}{ Stage } \\
\hline $0 /$ Tis & $<0.001$ & 1 & & \\
\hline I & 0.787 & 0.82 & 0.20 & 3.45 \\
\hline II & 0.315 & 2.06 & 0.51 & 8.37 \\
\hline III & 0.019 & 5.34 & 1.32 & 21.55 \\
\hline IV & 0.002 & 9.23 & 2.25 & 37.90 \\
\hline \multicolumn{5}{|l|}{ Grading } \\
\hline $\mathrm{G} 1 / 2$ & & 1 & & \\
\hline $\mathrm{G} 3 / 4$ & 0.096 & 1.15 & 0.98 & 1.35 \\
\hline \multicolumn{5}{|l|}{ R status } \\
\hline $\mathrm{R} 0$ & $<0.001$ & 1 & & \\
\hline $\mathrm{R} 1$ & $<0.001$ & 3.04 & 2.10 & 4.41 \\
\hline $\mathrm{R} 2$ & $<0.001$ & 4.45 & 3.33 & 5.94 \\
\hline \multicolumn{5}{|l|}{ Tumor histology } \\
\hline Classical adenocarcinoma & $<0.001$ & 1 & & \\
\hline Mucinous adenocarcinoma & 0.040 & 1.28 & 1.01 & 1.63 \\
\hline Signet-ring cell carcinoma & $<0.001$ & 4.04 & 2.41 & 6.77 \\
\hline Other rare types & $<0.001$ & 2.48 & 1.51 & 4.09 \\
\hline \multicolumn{5}{|l|}{ CEA (ng/ml, median) } \\
\hline $\mathrm{ng} / \mathrm{ml}$ (continuously) & $<0.001$ & $>1.00$ & 1.00 & $>1.00$ \\
\hline
\end{tabular}

After correction for tumor stage, R status, histology, and CEA, the tumor type was still an independent predictor of case-specific survival, with better prognosis for MCRC. HR hazard ratio, 95\% CI 95\% confidence interval

$p$-values in the heading line of each category indicate, if there is an overall difference between the groups when more than two specifications are possible. $p$-values in the same line with the respective specification compare the latter to the specification above 
Fig. 3 Trend analysis of the twelve patients who underwent resection of their initial primary colorectal cancer (PCRC) as well as for their metachronous colorectal cancer (MCRC) years later at our institution. Every line that illustrates more than just one patient is provided with the respective numbers of patients in this group. A relationship was identified neither for the TNM classification nor for the tumor grading. Regarding the M1-PCRC shown in the left lower panel, one patient with a primary carcinoma of the sigmoid and liver metastasis underwent combined resection (R0) but developed metachronous cancer of the ascending colon with a limited carcinomatosis peritonei 4 years later. He was alive without recurrence 2 years after the last operation
T status

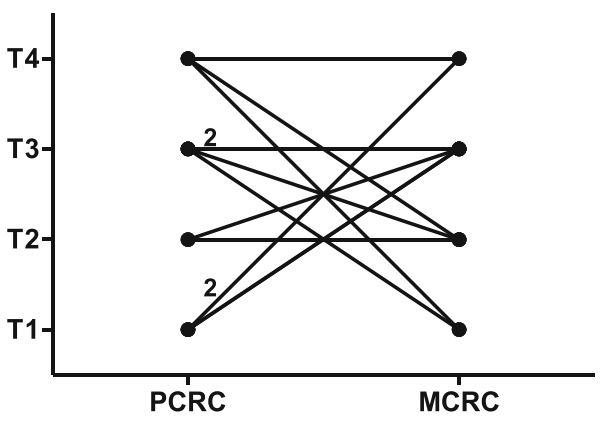

M status

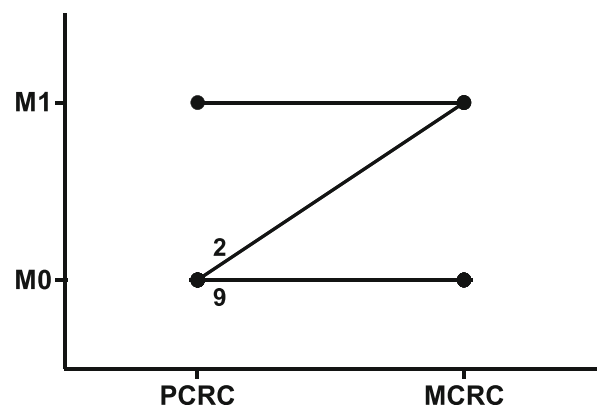

N status

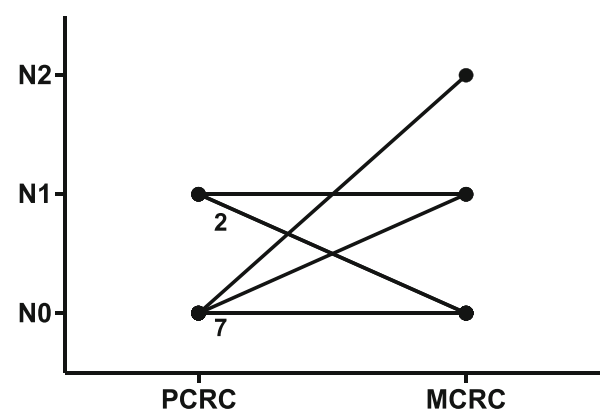

Grading

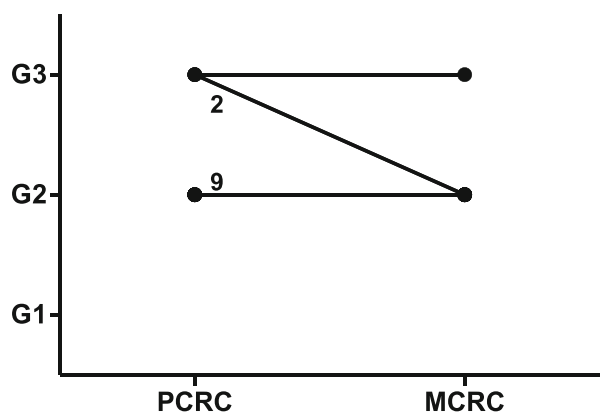

invasion; $p<0.001$; HR 3.28; 95\% CI 2.90-3.70), V1 (vascular invasion; $p<0.001$; HR 3.96; 95\% CI 3.36-4.67), non-R0 $(p<0.001$ for R1; HR 5.94; 95\% CI 4.53-7.79), microsatellite stable tumors ( $p=0.011$; HR $2.94 ; 95 \%$ CI $1.28-6.67)$, KRAS mutated tumors ( $p=0.011$; HR 1.93 ; 95\% CI 1.17-3.19), tumor perforation $(p<0.001$; HR 2.61 ; $95 \%$ CI $2.02-3.38)$, histological tumor type other than classical adenocarcinoma $(p<0.001$ for mucinous adenocarcinoma, signet-ring cell carcinoma, and other rare types, respectively), and CEA $(p<0.001$; HR 1.00 per $1 \mathrm{ng} / \mathrm{ml}$; $95 \%$ CI $1.00->1.00)$. A multivariable analysis was performed, which included all prognostic factors of the univariable analysis. Here, only tumor size, stable microsatellites, histological tumor type, and CEA remained independent significant predictors of survival (not shown). However, due to the reduced number of events (low absolute number of cause-specific deaths in the SCRC and MCRC group), another more robust multivariable analysis was performed, which only included the clinically most relevant factors. See Table 3 for the multivariable analysis. Here, MCRC was again identified as an independent favorable prognostic factor regarding cause-specific survival ( $p=0.005$; HR 0.25 ; 95\% CI $0.09-0.66$ ). In accordance to the abovementioned data, other poor prognostic factors upon this adjusted multivariable analysis were tumor length, UICC stage, $\mathrm{R}$ status other than R0, tumor histology, and CEA levels.

\section{Subgroups of special interest}

Of all documented patients, only twelve underwent resection at our department for both, the initial PCRC as well as for the MCRC at a later time point, without a clear risk profile regarding comorbidities or other factors. Eight of these were male, and four were female. The median age at the time of the first tumor manifestation was 68 years. Notably, the MCRC occurred after a median time of 9 years (range 3 to 19 years) after the PCRC. Regarding TNM classification and tumor grading, no correlation was identified between the PCRC and the corresponding MCRC. See Fig. 3 for trend analysis of patients resected for PCRC, followed by MCRC resection. All patients underwent another tumor resection, and none of these patients developed a third tumor manifestation during follow-up.

In total, only two patients were detected, who had a manifestation of metachronous colorectal cancer (MCRC) that presented as synchronous multiple colorectal cancer (SCRC). In specific, a 77-year-old male patient with rectal cancer diagnosed and resected about 35 years ago had now two tumor manifestations within the ascending colon. Additionally, a 91year-old female patient who had a T3N0M0 rectal cancer 5 years ago presented now with a tumor manifestation in the transverse colon, and another tumor manifestation in the rectum, which were not classified as a local recurrence. The first 
patient did not have recurrence of the disease after the second tumor resection until the last follow-up 90 months after surgery. However, the second patient with rectal cancer developed a tumor recurrence and finally died from systemic metastasis. For clarity and to avoid interference with the results, those two patients who could not clearly classifiable to MCRC or SCRC were not included in the further analysis, apart from their description in this paragraph.

\section{Discussion}

This study considerably enlarges the current knowledge of rare types of multiple colorectal cancers by providing a comprehensive analysis of more than 3500 patients with PCRC, SCRC, or MCRC, including clinical, histopathological, molecular genetics, and follow-up data. By analyzing a large collective over a period of 37 years, we did not detect any survival difference for patients with multiple synchronous colorectal cancers (SCRC) compared to patients with classical primary unifocal colorectal cancer (PCRC). However, patients with metachronous colorectal cancer (MCRC) had an improved prognosis, which was an independent factor in multivariable analysis.

Of all analyzed CRC patients, $2.8 \%$ had SCRC and MCRC. These findings as well as other baseline characteristics are in line with previously reported results, underlining the general validity of our data $[3,5,7,16]$. Of course, a limitation of the analysis is the retrospective and unicentric study design over a very long time, potentially leading to selection or treatment bias since the majority of initial cancers were not treated at the study institution. However, as no study intervention was performed and considering the high number of included patients, observational approach is deemed most appropriate in this context. Further, patients with HNPCC or APC may have been misinterpreted as sporadic SCRC or MCRC in this analysis. However, as determined by patient history, clinical assessment, genetic analysis in a part of the patients, and thorough follow-up, hereditary forms of colorectal cancer were excluded as far as possible in this study.

The improved survival for patients with MCRC compared to PCRC was the most relevant finding of our study and remains an object of discussion. This is the most comprehensive analysis hitherto existing, which reports not only on the incidence but also long-term survival of patients with sporadic metachronous colorectal cancer $[6,17]$. Possible explanations for an improved survival of MCRC patients are a positive selection of patients in this surgical cohort with locally restricted and resectable manifestations of the metachronous carcinoma. Also, stricter adherence to follow-up regimens after the second tumor manifestation could have improved early detection and treatment of secondary colorectal cancers and a higher patient compliance. Accordingly, lower T stages were found in the MCRC group, although not reaching a significant range. However, MCRC remained an independent favorable prognostic factor in the multivariable analysis (Table 3 ). Compared to the rectum, the tumors were more frequently located in the colon in patients with MCRC $(70 \%)$ than in patients with PCRC (59\%; see Table 2); however, tumor location (colon vs. rectum) was not a prognostic factor in this patient cohort ( $p=0.320$; Table 1). This would indicate other, potentially molecular genetic factors responsible for the improved prognosis of MCRC.

Observational studies report an elevated risk for MCRC after initial SCRC (HR 3-6) [6, 7]. Of note, two patients with SCRC were identified during data collection for this study, who developed a MCRC during follow-up. As reported above, these patients were not included within the analysis in order to prevent any possible selection bias. However, the estimated number of unreported cases is considerably higher due to admission to another hospital or misinterpretation as tumor recurrence.

In the subgroup of patients who were documented for both, resection of their PCRC and SCRC, a median interval of 9 years between the two tumor manifestations was observed. Earlier, Jayasekara et al. reported a mean interval of 4 years; however, the mean follow-up of our study was longer than the mean follow-up by Jayasekara et al. Thus, metachronous tumors after a longer interval may have been missed in the latter study. This finding raises the question for longer follow-up intervals than the usually performed 5 years, at least for selected patients at high risk for a MCRC (see Table 2).

\section{Conclusion}

Development and survival differences for PCRC, SCRC, and MCRC still cannot be fully explained. Current studies address factors arising from genetics (HNPCC, APC, IBD) [3, 5], environment (hypertension, hypoalbuminemia) [4, 6], and iatrogenic issues (tumor seeding during colonoscopy) [18].

Since this study identified metachronous colorectal cancers to develop even many years after the initial tumor, this exploratory study suggests that a programmed long-term follow-up may be the only pragmatic recommendation for patients with sporadic multiple colorectal cancers at present.

There are no large studies with validated prognostic or predictive factors available up to now. The retrospective study reported here may be prone to bias; thus further genetic and multicenter long-term studies are required.

Supplementary Information The online version contains supplementary material available at https://doi.org/10.1007/s00384-021-03926-6. 
Funding Open Access funding enabled and organized by Projekt DEAL.

\section{Declarations}

This study was performed in line with the principles of the Declaration of Helsinki. Approval was granted by the Ethics Committee of the Technical University of Munich, as stated in the methods part. The study report follows the STROBE statement for observational studies.

Conflicts of interest The authors declare no competing interests.

Open Access This article is licensed under a Creative Commons Attribution 4.0 International License, which permits use, sharing, adaptation, distribution and reproduction in any medium or format, as long as you give appropriate credit to the original author(s) and the source, provide a link to the Creative Commons licence, and indicate if changes were made. The images or other third party material in this article are included in the article's Creative Commons licence, unless indicated otherwise in a credit line to the material. If material is not included in the article's Creative Commons licence and your intended use is not permitted by statutory regulation or exceeds the permitted use, you will need to obtain permission directly from the copyright holder. To view a copy of this licence, visit http://creativecommons.org/licenses/by/4.0/.

\section{References}

1. Siegel R, Desantis C, Jemal A (2014) Colorectal cancer statistics, 2014. CA Cancer J Clin 64(2):104-117. https://doi.org/10.3322/ caac. 21220

2. Schmiegel W, Reinacher-Schick A, Arnold D, Graeven U, Heinemann V, Porschen R, Riemann J, Rodel C, Sauer R, Wieser M, Schmitt W, Schmoll HJ, Seufferlein T, Kopp I, Pox C (2008) Update S3-guideline "colorectal cancer" 2008. Z Gastroenterol 46(8):799-840. https://doi.org/10.1055/s-2008-1027726

3. Brenner H, Kloor M, Pox CP (2014) Colorectal cancer. Lancet 383(9927):1490-1502. https://doi.org/10.1016/S0140-6736(13) 61649-9

4. Chin CC, Kuo YH, Chiang JM (2019) Synchronous colorectal carcinoma: predisposing factors and characteristics. Color Dis 21(4):432-440. https://doi.org/10.1111/codi.14539

5. Lam AK, Chan SS, Leung M (2014) Synchronous colorectal cancer: clinical, pathological and molecular implications. World J Gastroenterol 20(22):6815-6820. https://doi.org/10.3748/wjg.v20. i22.6815

6. Jayasekara H, Reece JC, Buchanan DD, Rosty C, Dashti SG, Ait Ouakrim D, Winship IM, Macrae FA, Boussioutas A, Giles GG, Ahnen DJ, Lowery J, Casey G, Haile RW, Gallinger S, Le Marchand L, Newcomb PA, Lindor NM, Hopper JL, Parry S, Jenkins MA, Win AK (2016) Risk factors for metachronous colorectal cancer following a primary colorectal cancer: a prospective cohort study. Int J Cancer 139(5):1081-1090. https://doi.org/10. 1002/ijc. 30153

7. Kato T, Alonso S, Muto Y, Perucho M, Rikiyama T (2016) Tumor size is an independent risk predictor for metachronous colorectal cancer. Oncotarget 7(14):17896-17904. https://doi.org/10.18632/ oncotarget. 7555
8. Lindberg LJ, Ladelund S, Bernstein I, Therkildsen C, Nilbert M (2019) Risk of synchronous and metachronous colorectal cancer: population-based estimates in Denmark with focus on nonhereditary cases diagnosed after age 50. Scand J Surg 108(2): 152-158. https://doi.org/10.1177/1457496918798212

9. Samadder NJ, Curtin K, Wong J, Tuohy TM, Mineau GP, Smith KR, Pimentel R, Pappas L, Boucher K, Garrido-Laguna I, Provenzale D, Burt RW (2014) Epidemiology and familial risk of synchronous and metachronous colorectal cancer: a populationbased study in Utah. Clin Gastroenterol Hepatol 12(12):2078 2084 e2071-2072. https://doi.org/10.1016/j.cgh.2014.04.017

10. Nosho K, Kure S, Irahara N, Shima K, Baba Y, Spiegelman D, Meyerhardt JA, Giovannucci EL, Fuchs CS, Ogino S (2009) A prospective cohort study shows unique epigenetic, genetic, and prognostic features of synchronous colorectal cancers. Gastroenterology 137(5):1609-1620 e1601-1603. https://doi.org/ 10.1053/j.gastro.2009.08.002

11. Wu A, He S, Li J, Liu L, Liu C, Wang Q, Peng X, Zhou J, Cao PG, Cao K (2017) Colorectal cancer in cases of multiple primary cancers: clinical features of 59 cases and point mutation analyses. Oncol Lett 13(6):4720-4726. https://doi.org/10.3892/ol.2017.6097

12. Jayasekara H, Reece JC, Buchanan DD, Ahnen DJ, Parry S, Jenkins MA, Win AK (2017) Risk factors for metachronous colorectal cancer or polyp: a systematic review and meta-analysis. J Gastroenterol Hepatol 32(2):301-326. https://doi.org/10.1111/jgh.13476

13. Saville DJ (1990) Multiple comparison procedures - the practical solution. Am Stat 44(2):174-180

14. Nitsche U, Maak M, Schuster T, Kunzli B, Langer R, SlottaHuspenina J, Janssen KP, Friess H, Rosenberg R (2011) Prediction of prognosis is not improved by the seventh and latest edition of the TNM classification for colorectal cancer in a singlecenter collective. Ann Surg 254(5):793-800; discussion 800-791. https://doi.org/10.1097/SLA.0b013e3182369101

15. Nitsche U, Zimmermann A, Spath C, Muller T, Maak M, Schuster T, Slotta-Huspenina J, Kaser SA, Michalski CW, Janssen KP, Friess H, Rosenberg R, Bader FG (2013) Mucinous and signetring cell colorectal cancers differ from classical adenocarcinomas in tumor biology and prognosis. Ann Surg 258(5):775-782; discussion 782-773. https://doi.org/10.1097/SLA.0b013e3182a69f7e

16. Park SH, Lee JH, Lee SS, Kim JC, Yu CS, Kim HC, Ye BD, Kim MJ, Kim AY, Ha HK (2012) CT colonography for detection and characterisation of synchronous proximal colonic lesions in patients with stenosing colorectal cancer. Gut 61(12):1716-1722. https:// doi.org/10.1136/gutjnl-2011-301135

17. Chen TA, Horng JT, Lin WC (2013) Metachronous colorectal cancer in Taiwan: analyzing 20 years of data from Taiwan Cancer Registry. Int J Clin Oncol 18(2):267-272. https://doi.org/10.1007/ s10147-011-0373-5

18. Backes Y, Seerden TCJ, van Gestel R, Kranenburg O, Ubink I, Schiffelers RM, van Straten D, van der Capellen MS, van de Weerd S, de Leng WWJ, Siersema PD, Offerhaus GJA, Morsink FH, Ramphal W, Terhaar Sive Droste J, van Lent AUG, Geesing JMJ, Vleggaar FP, Elias SG, Lacle MM, Moons LMG (2019) Tumor seeding during colonoscopy as a possible cause for metachronous colorectal cancer. Gastroenterology 157(5):12221232 e1224. https://doi.org/10.1053/j.gastro.2019.07.062

Publisher's note Springer Nature remains neutral with regard to jurisdictional claims in published maps and institutional affiliations. 